\title{
A descolonização do olhar a partir do cinema de Lilian Solá Santiago
}

\author{
The decolonization of the perspective through the cinema of \\ Lilian Solá Santiago
}

\section{ANDRIELLE CRISTINA MOURA MENDES GUILHERME}

Universidade Federal do Rio Grande do Norte (UFRN), Natal - RN Brasil. Doutoranda e mestra pelo Programa de pós-Graduação em Estudos da Mídia da Universidade Federal do Rio Grande do Norte (PPgEM/ UFRN). https://orcid.org/0000-0002-

8977-4357

andriellecmmg@gmail.com

\section{DENISE CARVALHO}

Pesquisadora do Programa Nacional de Pós-Doutorado (PNPD/CAPES) vinculada ao Programa de Pós-

Graduação em Estudos da Mídia da Universidade Federal do Rio Grande do Norte (PPgEM/UFRN). Doutora em Sociologia pela Universidade de São Paulo (USP).

https://orcid.org/0000-0001-

7569-6127

denisecarvalho.mail@gmail.com

\section{JUCIANO LACERDA}

Universidade Federal do Rio Grande do Norte (UFRN), Natal - RN Brasil. Docente do PPgEM/UFRN, Doutor em Ciências da Comunicação (Unisinos, 2008), Pós-Doutorado pela UAB-Espanha (2017-2018). Doutor em Ciências da Comunicação pela Universidade do Vale do Rio dos Sinos (Unisinos, 2008). https://orcid.org/0000-00020876-377X juciano.lacerda@gmail.com

\section{RESUMO}

Apresenta-se uma análise fílmica do videodocumentário Roda o Tererê com vistas a investigar se e como o filme dirigido pela cineasta brasileira Lilian Solá Santiago contribui para uma descolonização do olhar, da estética e da política das imagens. Interessa identificar até que ponto o videodocumentário tensiona o regime de visibilidade dominante na sociedade nacional problematizado por teóricos localizados fora do eixo cultural da Europa (GONZALEZ, 2011; BORGES, 2018; NASCIMENTO, 2016). Conclui-se que, ao inscrever-se enquanto cineasta, Lilian Santiago não transforma a sua câmera apenas em voz; transforma o microfone em ouvido, e faz dele uma caixa de ressonância para que as pessoas ouçam e vejam aqueles que vem sendo historicamente apagados dos espaços do aparecer.

Palavras-chave: Mídia; Cinema; Descolonização do olhar

\section{ABSTRACT}

This paper reports a film analysis of the documentar Roda o Tererê in order to investigate whether the film directed by the brazilian filmmaker Lilian Solá Santiago decolonizes the perspective, the aesthetic and the politics of images and how these processes happens. It is interesting to identify the extent to which the documentary exerts tension on the regime of dominant visibility in national society, which has been problematized by theorists located outside Europe's cultural axis (GONZALEZ, 2011; BORGES, 2018; NASCIMENTO, 2016). The conclusion is that, when signing up as a filmmaker, Lilian Santiago doesn't turn her camera into a voice only; she turns the microfone into na ear and turns it into a speaker. Thus, people will year and see those who historically have suffered invisibility in the spaces of recognition.

Keywords: Media; Cinema; Decolonization of the perspective 


\section{UMA INTRODUÇÃO SOBRE A DESCOLONIZAÇÃO DO OLHAR}

Objetiva-se analisar até que ponto filmes dirigidos por cineastas negros (as) conseguem tensionar o regime de visibilidade dominante na sociedade brasileira ao promover uma descolonização da relação entre quem olha e quem é olhado. A palavra olhar extrapola aqui o sentido da visão, alcançando a dimensão da divisão de mundo, já que costumamos dividir o mundo para reduzir e dominar a sua complexidade.

Essa divisão é construída relacionalmente, visto que nascemos em um mundo que nasceu antes de nosso nascimento, habitado por palavras e imagens anteriores a nós - transmitidas por nossos pais, professores, amigos, autoridades, pela mídia -, que passam a compor um estoque de receitas de interpretação e orientação através das quais nos orientamos no mundo (SCHUTZ, 1979; LUHMANN, 2005).

A nossa sobrevivência está relacionada à nossa capacidade de interpretar um revólver apontado para nós como uma ameaça, por exemplo. Porém, a situação se complexifica a partir do momento em que passamos a interpretar um homem com um guarda-chuva como uma ameaça só porque esse homem é negro e está na favela, como aconteceu com o garçom Rodrigo Alexandre da Silva Serrano, assassinado por policiais militares, que dizem ter confundido um guarda-chuva com um fuzil (MOURA, 2018), sinalizando o quanto a articulação entre colonialismo e racismo vem moldando as lentes que usamos para interpretar o nosso entorno.

Borges (2019) observa que o século XXI tem sido marcado por tensões situadas na ordem do imaginário e discussões em torno das novas ordens de representação e novos regimes de visibilidade, como se vivêssemos numa constante guerra de imagens e signos, onde política e representação são cada vez mais indissociáveis.

As antigas ordens de representação estão em crise e se mostram, segundo a autora, incapazes de abarcar os "terrivelmente outros, não contemplados por uma concepção de humano e humanismo: negros e indígenas, asiáticos e africanos" (BORGES, 2019, p. 8), cujos corpos e culturas são devorados pela voracidade do olhar racista e sexista sem que haja uma redistribuição imaginária e real dos lugares dos sujeitos que têm o poder (os que olham e consomem) e dos que não têm (os que são vistos e são mercadorias de olhares) (BORGES, 2019).

O legado colonial ao longo do tempo atingiu comunidades inteiras, historicamente marcadas por um processo reiterado de manutenção do poder que reproduz legiões de indivíduos "excluídos, explorados, marginalizados, segregados dos espaços de poder social, cultural, econômico, político e educativo" (FIGUEIREDO, 2019, p. 87).

Este processo, na concepção de Silva (2019), é consequência de um conjunto de realidades construídas que atravessam a imagem, em um ciclo recorrente de estruturação das percepções 
e "das práticas sociais das nações colonizadas" (SILVA, 2019, p. 263) de um lado e do outro, por meio de uma cadência de "naturalização da exclusão visual de certos grupos sociais, tais como negros, indígenas, ciganos etc." (SILVA, 2019, p. 261).

A arte, ancorada na reconfiguração dos territórios do visível, do pensável e do possível (RANCIÈRE, 2005), desponta, dentro deste contexto, como horizonte para a transformação das implicações políticas do paradigma representativo contribuindo para aquilo que aqui chamamos de uma descolonização do olhar; uma prática vinculada à fabricação de imagens que abrem passagem para desafiar "as políticas de visibilidade e as noções de representação, levando em conta o que significou e significa o processo de colonização e dominação nos países marcados pela pior tragédia da humanidade: a escravidão" (BORGES, 2019, p. 27).

O sistema da colonialidade, que produziu no Ocidente séculos de escravização negreira e dizimação dos povos originários de cada lugar onde se colonizava, não se deu fora, mas dentro dos sistemas linguísticos, de acordo com Nascimento (2019), pois é por meio da capacidade da língua - e das múltiplas linguagens - que os sujeitos representam o mundo e agem sobre o mundo com seus falares (e seus mostrares), pois se a língua - e a linguagem (visual, verbal, verbo-visual) - foi criada pelo sujeito ao classificar o mundo, ela também cria o sujeito que, ao enunciar o mundo, se enuncia.

O epistemicídio - o assassinato do pensamento do outro -, conforme Nascimento (2019), se elabora, portanto, na linguagem (verbal, visual, verbo-visual) e na língua, e ganha um papel significante, quando apaga a possibilidade de os saberes tradicionais serem compreendidos, ouvidos e difundidos, operando, inclusive, através de mensagens veiculadas pelo cinema nacional que podem reforçar ou até mesmo duplicar preconceitos na medida em que ajudam a propagar um conjunto de veredictos instituídos pela sociedade, incluindo as percepções, observações pessoais, críticas construtivas ou negativas, intolerâncias, idiossincrasias e preconceitos dos seus realizadores, e difundir, em alguns casos, paradigmas estereotipados, geradores de preconceitos e intolerância para com os grupos historicamente marginalizados (SILVA, 2020).

Descolonizar o olhar, neste sentido, pode ser comparado ao ato de fazer emergir outras ordens de representação; de questionar a perspectiva, que recorta e orienta nossa visão de mundo -, principalmente quando a tela é emoldurada pelas pessoas negras e indígenas (BORGES, 2019), e de adotar, pela via do regime estético, olhares capazes de problematizar a maneira como uns e outros participam da partilha do sensível, disputando o que se pode dizer sobre o que é visto, segundo Rancière (2005).

Em meio a essa disputa de imagens por outros imaginários, a proposta trazida neste artigo é investigar se e como o filme dirigido pela cineasta brasileira Lilian Solá Santiago contribui para a visibilização dos modos de ser, dizer e fazer dos povos indígenas e negros, historicamente apartados, pela via do racismo sistêmico, dos espaços do aparecer. 
Interessa identificar até que ponto o cinema de Lilian Santiago tensiona o regime de visibilidade dominante na sociedade nacional e contribui para uma descolonização do olhar. Para isso, realiza-se uma análise fílmica com foco no conteúdo do videodocumentário Roda o Tererê - A erva mate no Mato Grosso do Sul, a fim de compreender se e como a obra audiovisual contribui para apreender e desvelar aspectos do cotidiano antes desconhecidos, transmutando à perspectiva do visível "aspectos da sociedade por vezes à margem, difusos ou ostensivos" (RAMOS, 2003, p. 36).

\section{METODOLOGIA}

A análise fílmica, explica Manuela Penafria (2009), inicia-se pela decomposição do filme, descrevendo-o, em primeiro lugar, para depois estabelecer relações entre os elementos decompostos. "Trata-se, acima de tudo, de uma atividade que separa, que desune elementos" (PENAFRIA, 2009, p. 2) para depois articulá-los e interpretá-los e "fazer uma reconstrução para perceber de que modo esses elementos foram associados num determinado filme" (PENAFRIA, 2009, p. 2).

Ramos (2003) ressalta a importância do método fílmico em um contexto como o atual, marcado por uma profusão de transformações sociais e tecnológicas que atravessaram os campos da comunicação, da informação e mesmo da pesquisa científica, culminando no desdobramento "das possibilidades de observação e de análise" (RAMOS, 2003, p. 45). Neste sentido, como recurso metodológico, a observação fílmica também permite a possibilidade de investigação acerca das "representações sociais dos indivíduos e grupos" (RAMOS, 2005).

A decomposição é um ponto de partida para se chegar à uma interpretação que não seja nem despropositada nem pouco pertinente. Para tanto, a análise deve ser realizada tendo em conta objetivos específicos, já que se trata de uma atividade que exige uma observação rigorosa, atenta e detalhada a, pelo menos, alguns planos de um determinado filme (PENAFRIA, 2009). A análise fílmica como método fornece uma diversidade de elementos passíveis de apreensão por meio da "aliança da observação e da escuta, da linguagem verbal e não verbal que a imagem em movimento, que o documento fílmico proporciona" (RAMOS, 2005, p. 365), tal como um "microscópio ou um espelho mágico" (RAMOS, 2005, p. 366).

Manuela Penafria (2009) cita quatro possíveis tipos de análise: a análise textual; a análise de conteúdo; a análise poética e a análise da imagem e do som. Enquanto a análise textual 
considera o filme como um texto, dividindo-o em segmentos, a análise de conteúdo considera o filme como um relato e tem apenas em conta o tema do filme. Neste tipo de análise, explica Penafria (2009), a decomposição é feita tendo em conta o que o filme diz a respeito do tema.

Já na análise poética, o filme é entendido como uma programação/criação de efeitos. Neste tipo de análise, se enumera os efeitos da experiência fílmica (sensações, sentimentos e sentidos) que um filme é capaz de produzir no momento em que é visto para depois interpretar como esses efeitos foram construídos.

Enquanto isso, na análise da imagem e do som, o filme é entendido como um meio de expressão, que permite pensar e lançar novos olhares sobre o mundo, tendo em vista o conjunto de relações nos quais decorreu a sua produção e realização, como, por exemplo, o contexto social, cultural, político, estético, tecnológico.

Os quatro tipos de análise costumam se interpenetrar, embora seja sempre possível destacar um ou mais aspectos, dependendo dos objetivos. Na análise fílmica apresentada a seguir, por exemplo, destacamos os aspectos relacionados ao conteúdo do filme Roda Tererê - A ervamate no Mato Grosso do Sul, dirigido por Lilian Solá Santiago, documentarista, pesquisadora e professora de Cinema e Audiovisual. Doutoranda na ECA-USP - Programa de Meios e Processos Audiovisuais, desde 2019.

Lilian Santiago é mestre em Integração da América Latina (2005) e possui Graduação em História (1998), na mesma universidade. Dirigiu vários filmes documentários ganhadores de importantes prêmios no Brasil e no Exterior, tais como "Família Alcântara" (2006), "Balé de Pé no Chão" (2006), "Graffiti" (2009), "Eu tenho a palavra" (2011) e "Fios do Passado" (2015). Atua como professora-cineasta no Curso de Cinema do Centro Universitário Nossa Senhora do Patrocínio (CEUNSP), em Salto - SP, desde 2010, onde coordena e orienta a realização de filmes de curta metragem da Kimera Filmes, produtora experimental do Curso.

Em Salto, também organiza o Curta Salto - Festival de Cinema de Salto, que está em sua sétima edição. Em 2014, foi uma das ganhadoras da Bolsa Funarte de Fomento aos Artistas e Produtores Negros, com o projeto multimídia "Casa da Memória Negra de Salto" (2016-2020), um documentário expandido para inserção da história e cultura afro-brasileira na exposição permanente do Museu da Cidade de Salto Ettore Liberalesso, ativado mensalmente pelo sarau e café coletivo "Café com Pretos". Como pesquisadora, participa do Lab-Arte-Mídia (Laboratório de Arte, Mídia e Tecnologias Digitais), na ECA-USP, sob coordenação do Professor Doutor Almir Almas, desde 2017. 


\section{O TRAÇAR DE UMA ANÁLISE FÍLMICA DE CONTEÚDO EM RODA O TERERÊ - $A$ ERVA-MATE NO MATO GROSSO DO SUL}

Dirigido pela cineasta e educadora audiovisual Lilian Solá Santiago, o documentário Roda o Tererê - A Erva-mate no Mato Grosso do Sul foi produzido em 2009, no Brasil, com recursos do Instituto do Patrimônio Histórico e Artístico Nacional IPHAN/Ministério da Cultura disponibilizados para o projeto de Inventário de Referências Culturais do Erval Sulmatrogrossense, com realização do Departamento de Patrimônio Imaterial da Superintendência do IPHAN no Mato Grosso do Sul e execução da Terra Firme Digital.

No filme, Lilian Solá Santiago responde pela pesquisa, roteiro e direção; Gabriela Ferrite responde pela produção executiva; Maurício Copetti, pela Fotografia e Câmera; Michelle Britto, pela edição e Gabriela Watson, pela transcrição. O documentário é alinhavado a partir dos depoimentos de Celito Espíndola, Emmanuel Marinho, Neimar Machado de Souza, Menegilda Ortega, Gilson Martins, Alan Sciamarelli, Carla Centeno, Gregório Lugo, Aparecido Justiniano, Valdelice Verón e o Cacique Carlito Paulo.

Além das imagens captadas sob a direção de Lilian Santiago, o documentário (com duração de 18 minutos e 33 segundos), é construído também a partir do arquivo de fotos do Arquivo Público Estadual de Mato Grosso do Sul (coleção Mate Laranjeira), das gravuras de José Flávio Lemos Fontão e de cenas do filme Selva Trágica - dirigido por Roberto Farias com produção da R.F. Cinema e TV Ltda. 


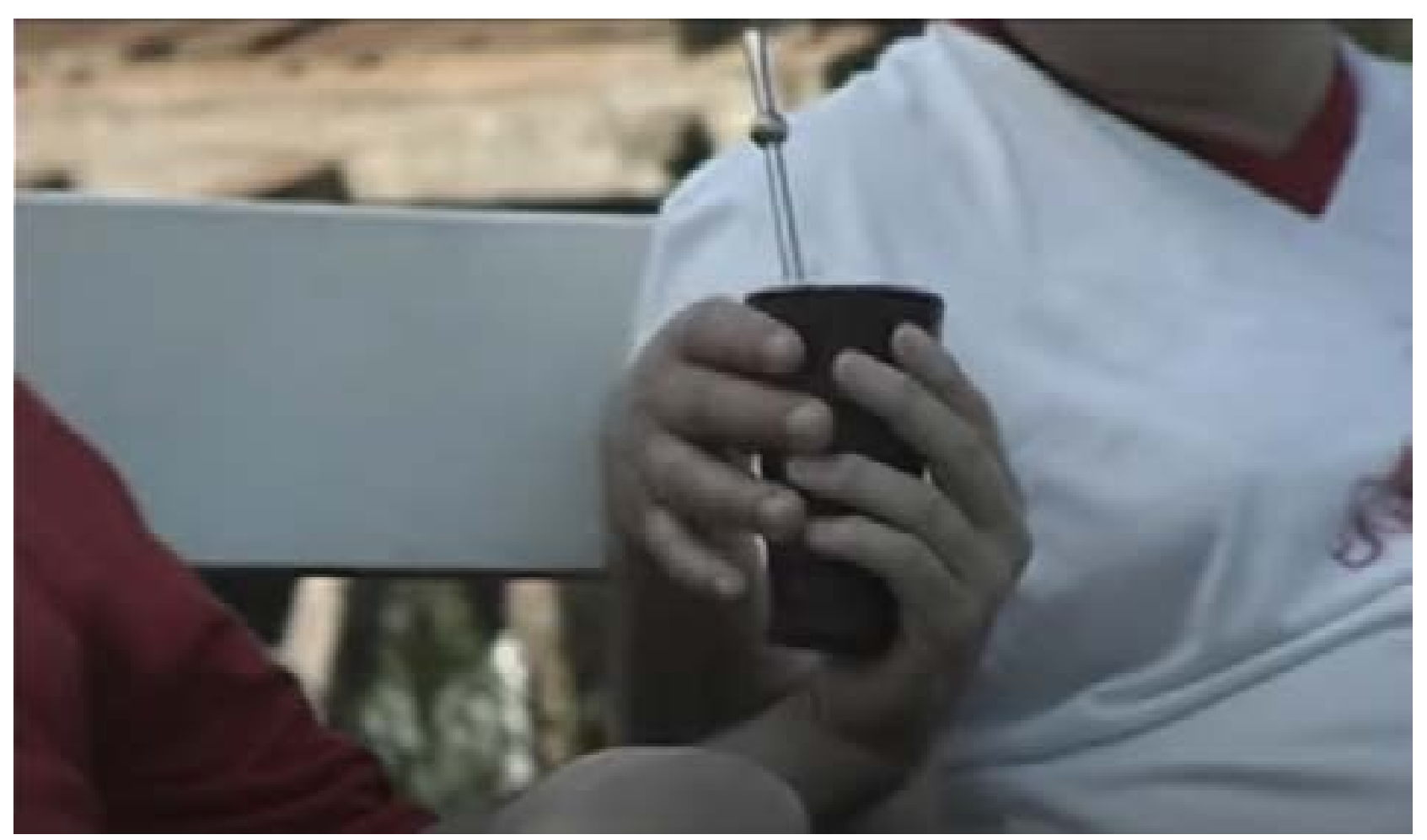

FIGURA1: Frame do videodocumentário Roda o Tererê (0'28').jpg Fonte: Elaboração própria a partir do print da tela.

Desde o início, Roda o Tererê chama os seus espectadores a uma viagem à conexão entre a erva-mate e seus admiradores. O consumo da erva no cotidiano assume um aspecto ritualístico, de compartilhamento não apenas da erva, mas de um momento de interação entre seus usuários, como coparticipes de uma tradição, que remonta ao século XIX.

Os primeiros minutos do filme remontam historicamente o processo de beneficiamento de uma erva que, em sua origem, teve destaque no campo produtivo do Mato Grosso do Sul (MS) a ponto de tornar seu estado de origem um exportador para países vizinhos, como a Argentina, por exemplo. Paradoxalmente, o primeiro contraponto é apresentado: de exportador, o MS foi convertido em importador, como consequência do desmatamento dos vastos territórios nativos da erva. A jornada proposta por Lilian Santiago remonta a forma como se deu este processo.

O processo predatório de exploração da erva-mate tem início após a Guerra do Paraguai, em 1870, quando a produção da erva é convertida em monopólio da empresa gaúcha Mate Laranjeira Mendes S.A. Finda a descrição dos procedimentos relacionados ao processamento da erva, a obra transpassa os demais elementos culturais presentes na região do Mato Grosso do Sul, principalmente na música, na dança e nos gritos comemorativos do seu povo. 
O despertar da autossuficiência do mercado argentino começa a influenciar na decadência da Mate Laranjeira, desencadeando um processo de proletarização entre todas as pessoas envolvidas naquele processo produtivo. Paradoxalmente, em meio à disseminação de uma carga simbólica bastante negativa com relação ao consumo da erva, associado ao risco de excomunhão e de sujeição à Inquisição sobre as pessoas que fossem flagradas utilizando a erva em público. Este encadeamento foi promovido pelo fato da erva ser estimulante e, por isso, associada a práticas demoníacas, reprovadas pelos preceitos morais defendidos pela Igreja Católica.

A despeito desta carga simbólica pejorativa, as Missões europeias do século XVII especialmente, as espanholas - já apontavam para o alto potencial de consumo desenvolvido pelas Missões da região (Guairá e Itatim). Entre 1620 e 1630, o consumo da erva-mate é consolidado nos centros coloniais em Buenos Aires, no Uruguai, em Tucumã e em Assunção. Um dos fatos que comprova a ascensão da erva é exemplificado no nome de uma das missões da região, denominada de Santiago de Caaguaçu (onde Caa significa erva e Guaçu significa grande).

A forte relação da localidade com a forma como a erva é nomeada pelos indígenas revela um aspecto invisibilizado: sua origem indígena, tanto com relação à territorialidade, quanto com relação ao ritual da colheita, do processamento e do consumo da erva-mate. Chegamos ao ponto de virada do filme! O enquadramento na aldeia convida seus espectadores a contemplar os campos do erval em território Guarani Kayowá, agora desmatados. Os instrumentos, as músicas, as cores demonstram a profunda relação de toda a relação da erva com os saberes da comunidade Guarani.

O aspecto meramente produtivo da erva posto em prática pelas Missões é agora transmutado ao profundo aspecto de ligação da erva com o transcendente entre os indígenas, anteriores a todas as Missões. Neste ponto, o esfacelamento físico dos ervais denuncia o também esfacelamento da própria identidade do povo Guarani, revelando a identificação de um genocídio cultural (NASCIMENTO, 2016) deste povo nativo, em decorrência da expansão agropastoril das fronteiras sul-mato-grossenses.

Para contar essa história, Lilian Solá Santiago escolheu variadas locações: o mercado público, a fábrica de erva mate em Caarapó (MS), o museu, a casa/comunidade de entrevistados, a biblioteca, o território indígena Guarani. A cineasta afirma ter mergulhado fundo no patrimônio imaterial do Mato Grosso do Sul, principalmente no que se refere ao uso da erva-mate, suas origens e seus costumes, para realizar o videodocumentário (SANTIAGO, 2009).

Apesar da mudança das locações, as cenas se caracterizaram por uma imobilidade marcada predominantemente pela opção pelo plano médio (quando a câmera está a uma distância média do referente; da pessoa ou do objeto filmado), do plano fechado (quando a câmera está próxima do referente), ângulo normal ou 3/4 (quando a câmera está apontada para o nariz da pessoa 
filmada ou em um ângulo de 45 graus) e pela posição dos entrevistados, que ora aparecem sentados ora aparecem em pé sem sair do lugar, salvo nas cenas filmadas na aldeia Guarani Taquara, como na cerimônia do Caa (nome indígena guarani da erva-mate), como é possível observar nas imagens abaixo:

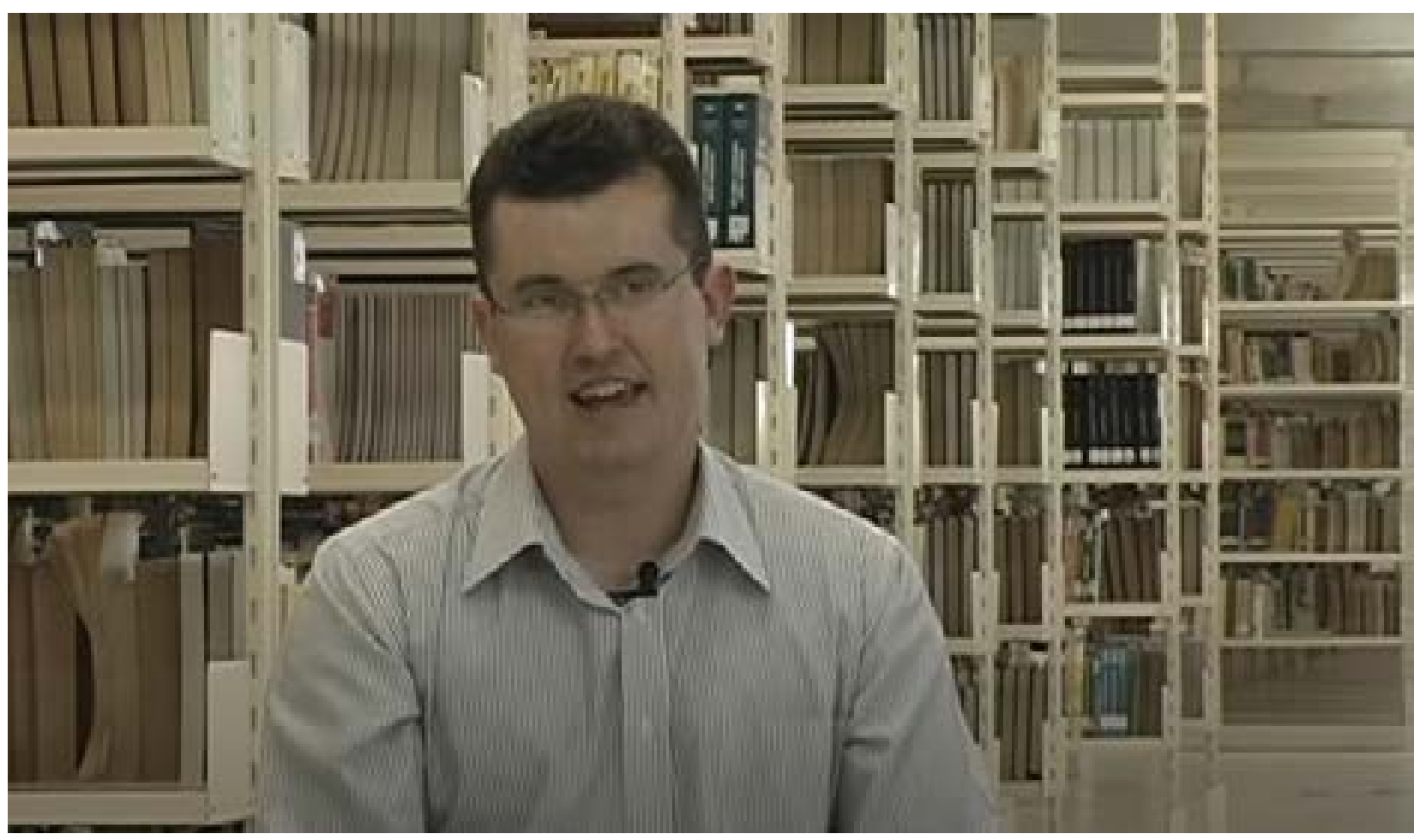

FIGURA2: Frame do videodocumentário Roda o Tererê (16'59").jpg Fonte: Elaboração própria a partir do print da tela. 


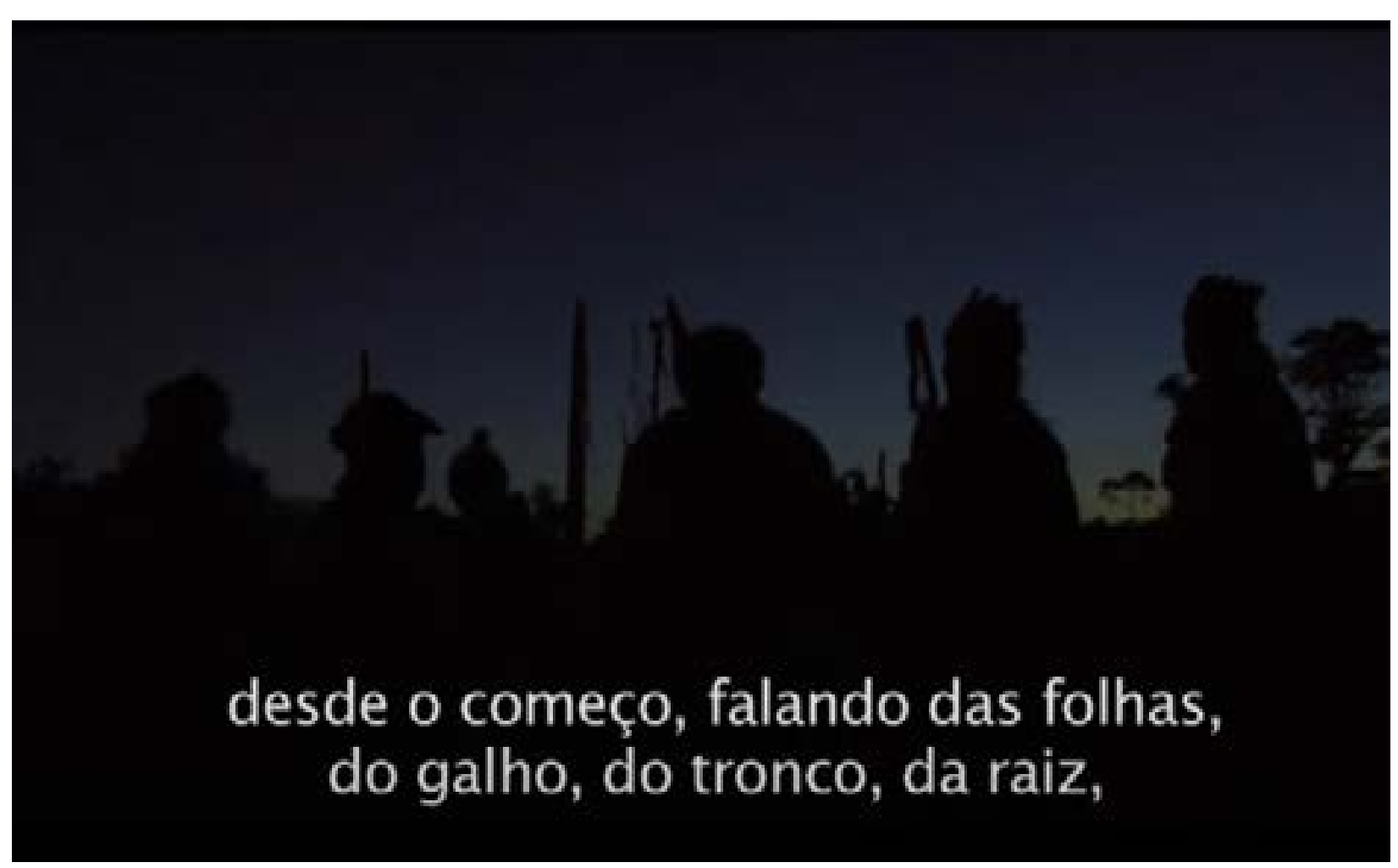

FIGURA3: Frame do videodocumentário Roda o Tererê (14'42").jpg Fonte: Elaboração própria a partir do print da tela.

A imobilidade do corpo do historiador Neimar de Souza, sentado entre os livros, contrasta com a mobilidade dos corpos dos indígenas Guarani, cujos nomes não são revelados no videodocumentário. A contraposição das duas cenas sugere que a história não está só dentro da biblioteca, mas também fora dela, num aqui agora difícil de capturar, já que, em meio a penumbra, não conseguimos ver o seu rosto.

As histórias extraoficiais, as histórias que se desenrolam neste aqui agora, as histórias dos povos historicamente silenciados, são difíceis de capturar, porque são movimento contínuo, e não uma disciplina estanque como a História oficial parece ser. Envolta na penumbra de um momento que nem é dia nem é noite, as histórias-movimento só exibem seus rostos e dizem seus verdadeiros nomes para aqueles que aceitam entrar na roda e participar da sua dança. Talvez por isso, no videodocumentário, o historiador oficial apareça num local iluminado, controlado, ordenado, disciplinado, enquanto a história extraoficial se desenrola, diante de nossos olhos, envolta em sombras, fumaça e penumbra durante a cerimônia de Caa, apontada por Lilian, como ponto alto da obra audiovisual.

O apagamento da origem indígena da prática de partilhar o tererê borra o caráter espíritosocio-cultural dessa prática ainda hoje cultivada pelos indígenas Guarani, que em suas "danças, 
embebedados pela erva-mate ou por outra bebida tradicional, que causa uma certa excitação, divertem-se e entram em contato com os espíritos. (Enquanto) O pajé, costumeiramente, toma a bebida para prever o futuro ou curar" (POTIGUARA, 2019).

A relação de respeito do povo Guarani com a erva mate é enfatizada no depoimento do cacique Carlito Paulo (Aldeia Taquara), quando ele diz que a erva não é apenas uma árvore para o povo Guarani; a erva é como se fosse alguém, que sempre cuidou da nossa terra.

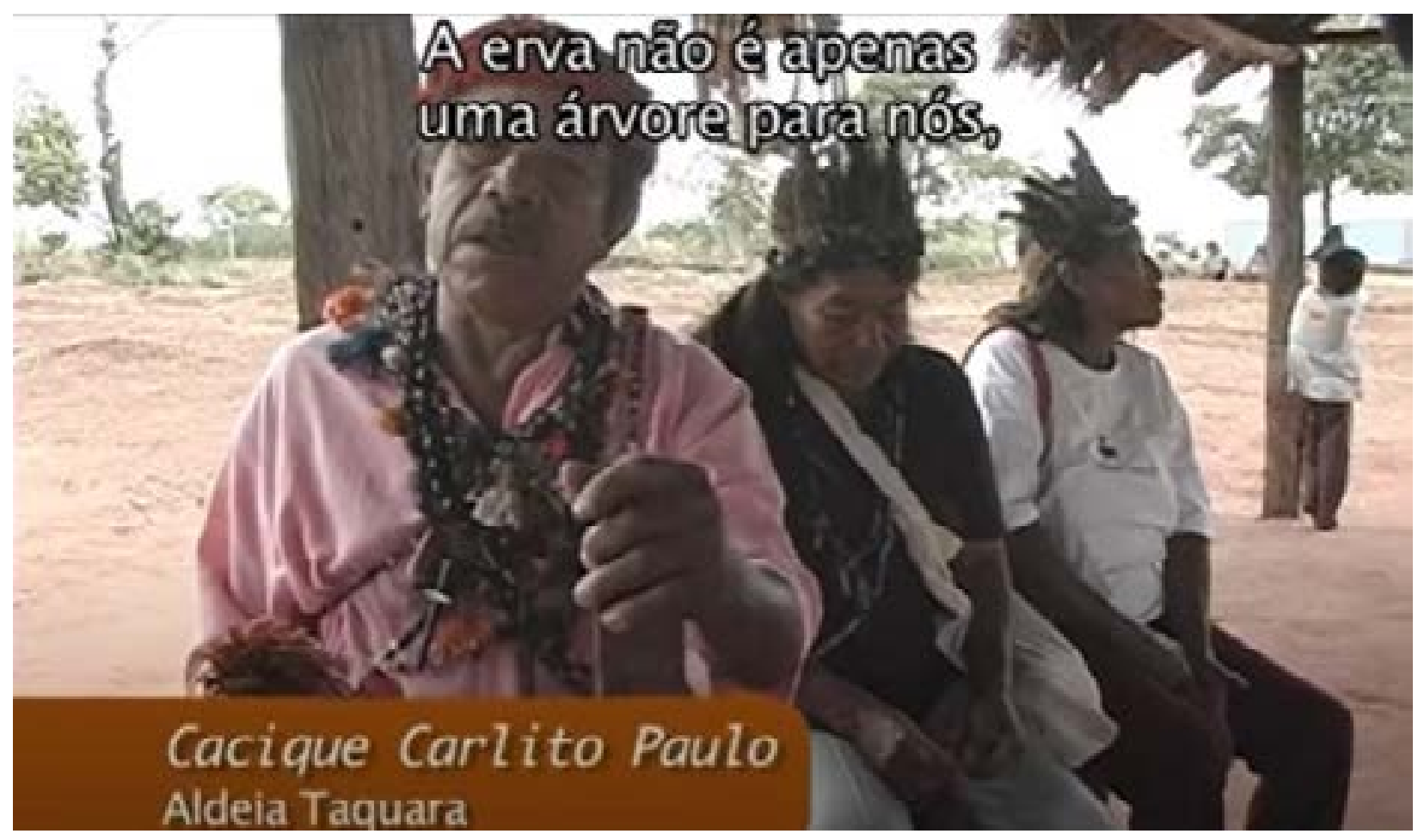

FIGURA4: Frame do videodocumentário Roda o Tererê (13'18').jpg Fonte: Elaboração própria a partir do print da tela.

Cacique Paulo, ao falar sobre a transmissão intergeracional do canto, das rezas e do ritual da erva, corporifica os depoimentos dos historiadores entrevistados no videodocumentário e evoca algo também mencionado por Valdelice Veron no filme: a atemporalidade da prática social. É dessa conexão atemporal do território com a ancestralidade, que vem a resistência para reivindicar os direitos a permanecer num território (POTIGUARA, 2019), que é transfronteiriço e anterior ao Estado Nacional.

Ao desinvisibilizar as contribuições do povo Guarani Kayowá para a cultura imaterial do Mato Grosso do Sul, o filme Roda o Tererê ajuda a abrir fissuras na colonialidade do saber e do poder (QUIJANO, 2005), que insiste em apagar os saberes dos povos originários na construção 
de sentidos e práticas sociais, que estruturam a sociedade nacional, criando, com a câmera, um espaço onde vozes há muito silenciadas possam, enfim, ser ouvidas no seu idioma originário. Não se trata, na obra audiovisual, de respeitar apenas o que o "outro" (BORGES, 2019) diz, mas também de respeitar como ele diz o que diz.

Lilian Solá Santiago usa, dessa forma, a sua lente para garantir o direito ao aparecimento de populações historicamente apagadas, seja pela violência física, que arrasa os corpos e territórios, seja pela violência simbólica, que apaga as contribuições das populações originárias na produção e reprodução de cultura e conhecimento, pois, como lembra Eni Orlandi (1990), o silenciamento e apagamento impostos desde o período colonial não incide apenas sobre o que o indígena, enquanto sujeito, faz, mas sobre a própria existência do sujeito indígena.

A forma que Lilian escolhe para representar o povo Guarani Kayowá transmite uma ideia de persistência na História: desde o encontro dos artefatos nos sítios arqueológicos, passando pelos ervais da Mate Laranjeira, até a cerimônia do Caa na aldeia durante a realização do documentário. Esta ideia de persistência na história, de atemporalidade, pode ser observada na cena abaixo:

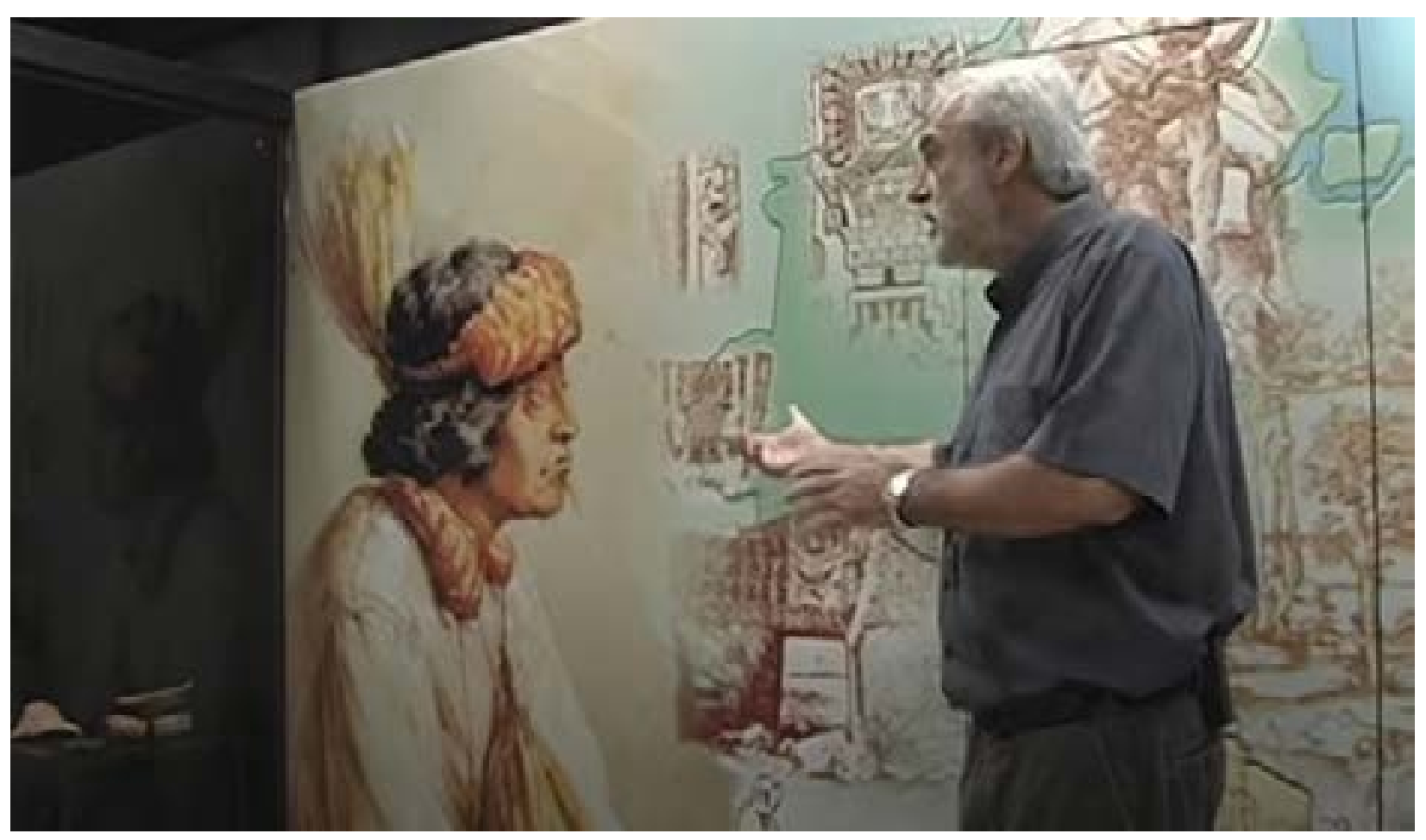

FIGURA5: Frame do videodocumentário Roda o Tererê (15'55').jpg

Fonte: Elaboração própria a partir do print da tela. 
Nesta cena, o arqueólogo Gilson Martins parece interpelar o indígena, cujo nome não é revelado no videodocumentário. O corpo do arqueólogo (pernas, braços, mãos, tronco, rosto) está voltado para o indígena, cujo olhar não se deixa capturar. O olhar do Guarani sugere cansaço, tristeza, desamparo, indiferença. Parece perdido no tempo. O indígena, diferentemente do arqueólogo, tem um reflexo, um duplo, que olha para trás.

Os traços da boca, nariz, olhos desse duplo aparecem borrados, desfocados, lembrando rastros, que se apagam à medida que se percorre um caminho, distanciando-se da origem. Esta é uma das últimas cenas do filme. Pouco depois dela o historiador Neimar Souza reaparece dentro da biblioteca.

O depoimento dele é o escolhido para transmitir a mensagem final (e principal) do filme e alinhavar o começo, o meio e o fim da narrativa audiovisual. Neimar traz para o desfecho do videodocumentário a memória de como e onde o hábito de compartilhar o tererê surgiu.

(In)vestido como doutor da História, em meio a livros e documentos, atesta a origem Guarani dessa prática social, que se transformou em um símbolo da cultura imaterial do Mato Grosso do Sul. O filme, desse modo, costura nas entrelinhas, a violência até hoje imposta ao povo Guarani, um povo que é mais antigo que vários países, e mesmo assim, até hoje, morre, geralmente longe da visão da população não-indígena, por defender o direito de viver em sua terra ancestral.

O depoimento de Neimar lembra Quijano (2005), quando este ressalta que, ao desembarcar na América Latina, os ibéricos encontraram diferentes povos, cada um com sua própria história, linguagem, descobrimentos e produtos culturais, memória e identidade, que acabaram reduzidos a uma única identidade - índios - com o apagamento de singularidades e identidades históricas (QUIJANO, 2005), pois essa nova identidade racial, colonial e negativa implicava o despojo de seu lugar na história da produção cultural da humanidade.

A ideia colonial de raça vem sendo, desde então, instrumentalizada para legitimar as relações de dominação e, assim, justificar a invasão de territórios ocupados pelos povos nativos e/ou tradicionais, provando ser uma das invenções mais duradouras do colonialismo. É neste sentido que as lentes da câmera de Lilian Solá Santiago se transformam em um instrumento antirracista e descolonial, que ajuda a retirar da invisibilidade as contribuições originárias que a colonização tentou apagar física e simbolicamente. 


\section{A RELEVÂNCIA DE UMA MIRADA AMEFRICANIZADA PARA A IDENTIFICAÇÃO DOS INSTRUMENTOS DE DOMINAÇÃO COLONIAL EM RODA O TERERE}

O despertar de um olhar amefricanizado com vistas à descolonização do olhar, inspirado na proposta afro-latino-americana de Lélia Gonzalez (2001) contribui, de início, para o reconhecimento de contradições internas que revelam a persistência de desigualdades profundamente enraizadas na sociedade brasileira (GONZALEZ, 2001) e, em uma fase seguinte, na implementação de medidas que favoreçam a redução e, em um sistema ideal, a eliminação destas.

Nascimento (2016) identificou na vivência do povo negro uma série de processos de destituição de sua condição de condutores e criadores de uma cultura própria. O cinemadocumentário de Lilian Santiago explicita este processo apontado por Nascimento (2016) na vivência da comunidade indígena, ao demonstrar como a dinâmica historicamente progressiva da dominação colonial culminou na destituição do povo Guarani Kayowá de sua condição enquanto agentes responsáveis pela criação e condução de uma cultura própria relacionada à erva-mate.

Os aportes históricos trazidos no documentário revelam que a estratégia colonial instrumentaliza este processo de destituição por meio do desmatamento e da exploração predatória das plantações de erva-mate em território Guarani, em busca pela obtenção do lucro para a consolidação do monopólio de mercado, ao ponto do Estado do Mato Grosso do Sul se transmutar de principal fornecedor a importador da erva em questão de anos.

A comunidade indígena é destituída não apenas dos meios sociais de produção da erva, mas também da perpetuação de uma dinâmica muito particular de sua relação com a comunidade, que transcende o consumo, atravessando a esfera da cultura. Roda o Tererê desvela uma relação ecosimbiótica entre: a) o território, as folhas, os galhos, o tronco e a raiz da erva-mate e b) os saberes e a relação com o transcendente da comunidade Guarani, sugerindo uma mirada já apresentada por Nascimento (2016), que denuncia a imposição de uma cultura (colonial) sobre outra cultura anterior (ancestral).

Filha de uma sociedade ibérica, a sociedade brasileira herdou o legado de ser composta por uma estrutura social altamente hierarquizada (GONZALEZ, 2011), que revela uma estratificação em múltiplos sentidos, inclusive no âmbito da hierarquia entre práticas religiosas advindas das sociedades ibéricas em contraposição às práticas religiosas de grupos não-cristãos. Esta estratégia simbólica reforça tentativas recorrentes de infantilização, exploração e subalternização de negros e indígenas em território brasileiro (GONZALEZ, 2011).

O olhar apresentado na obra de Lilian Santiago demonstra as consequências legais direcionadas aos indivíduos - e, no limite, a prisão - dos que fossem vistos consumindo o Tererê, sob a justificativa do consumo de uma substância estimulante e, sob a ótica do olhar colonial, como demoníaca. 
A multiplicidade de fatores resultante desta mirada amefricanizada em Roda o Tererê traz à tona elementos que despertam semelhantemente um olhar para que seja possível observar em que medida os instrumentos de dominação colonial contribuem para a desintegração cultural (NASCIMENTO, 2016) e para a apropriação cultural de uma cultura sobre outra, no sentido de promover "o esvaziamento de significados e apagamento dos traços da cultura de origem de um povo" (WILLIAM, 2019, p.29).

Os meios audiovisuais, afirma Cusicanqui (2015), por sua vez, seriam uma chave para descolonizar o olhar e comunicar as subjetividades emergentes portadoras de concepções de mundo e epistemes alternativas por conseguirem tocar a sensibilidade de um modo que a escrita não consegue. A questão é que, de acordo com a Agência Nacional de Cinema (Ancine), apenas $2,1 \%$ dos longa-metragens lançados comercialmente no país em 2016 foi dirigido por homens negros e nenhum por mulheres negras.

O levantamento ilustra como a descolonização da estética não se dissocia da política, pois negros e indígenas não são minorias apenas na frente das telas e por trás das câmeras, mas também em todos os espaços de saber e poder, mesmo sendo maioria populacional, se considerarmos a soma de todas as pessoas racializadas (pretos, pardos, indígenas) no país.

Isso faz com que a descolonização, segundo Samia Mehrez (1991), se torne um imenso processo de liberação histórica e cultural, por configurar um ato de confrontação com um sistema de pensamento hegemônico e se tornar a contestação de todas as formas e estruturas dominantes, sejam elas linguísticas, discursivas ou ideológicas (e imagéticas).

A descolonização do olhar, conforme afirma Cusicanqui (2015), pode ser fortalecida por meio de uma prática reflexiva, comunicativa e coletiva a partir da combinação entre ação, ideação, imaginação e pensamento com vistas a uma reatualização/reinvenção da memória coletiva (CUSICANQUI, 2015).

O documentário Roda o Tererê opera, dentro desse quadro, como um meio de reparação histórica, ao mostrar que o hábito de tomar mate vem do povo Guarani, um dos maiores povos indígenas do Brasil, somando, aproximadamente, 67.500 pessoas distribuídas nos estados do Mato Grosso do Sul, Espírito Santo, Rio de Janeiro, São Paulo, Paraná, Santa Catarina e Rio Grande do Sul e também na Argentina, Uruguai, Paraguai e Bolívia (POTIGUARA, 2019), pois o filme não se limita a mover apenas imagens visuais, mas ajuda a mobilizar, enquanto campo de partilha do comum, imagens mentais, que alimentam imagens visuais e por elas são retroalimentadas.

A mirada de Lilian Santiago, nesse sentido, contribui para a abertura de outros caminhos possíveis para a descolonização do olhar por meio da fabricação de uma nova política estética e ética das imagens, que alarga a participação do comum através de uma partilha antirracista do sensível; um antirracismo que contempla tanto a população negra quanto os povos indígenas no Brasil. 
As escolhas verbo-visuais de Lilian, materializadas através da linguagem audiovisual, endossam a tese de Nascimento (2019), de que a linguagem não é apenas um espaço de colonialidade e epistemicídio, mas também espaço de emancipação dos grupos historicamente marginalizados. É mirando a partir dessa perspectiva que o cinema negro (e também o indígena) pode ser apontado como uma das ferramentas para inventar o mundo (SIMAS; RUFINO, 2019).

Simas e Rufino (2019) enxergam a linguagem tanto como uma plataforma de instauração do racismo como também rota de fuga daqueles que são submetidos a esse sistema de poder; uma rota, que segundo eles, pode contribuir para a emergência de ações antirracistas/ descolonizadoras, se considerarmos a descolonização enquanto ato de responsabilidade com a vida em sua diversidade e imanência, ato de transgressão ao sistema de subordinação dos seres/ saberes e resiliência daqueles que são submetidos ao colonialismo, ao espectro de terror, política de morte e desencanto que se concretiza na bestialidade, no abuso, na produção incessante de trauma e humilhação (SIMAS; RUFINO, 2019).

Por esta ótica, quando Lilian Santiago abre a lente para enfocar o povo Guarani Kayowá, ela fissura a lógica colonialista por trás da estereotipização, essencialização, coisificação e desumanização dos povos indígenas, que só no Brasil se subdividem em 370 etnias falantes de mais de 274 línguas, sem considerar os povos isolados e desconhecidos. É nesta perspectiva, que a obra audiovisual de Lilian pode ser considerada descolonial, conforme a definição de Simas e Rufino (2020).

A cineasta não fala pelo povo Guarani, mas abre o microfone para que eles falem por eles próprios e se expressem na sua língua e nos seus termos. Ela não usa a linguagem audiovisual para falar sobre o povo Guarani Kayowá; ela usa o cinema para falar com o povo Guarani Kayowá, numa perspectiva antirracista e descolonizadora, nos enredando na discussão sobre o papel da linguagem na manutenção do racismo estrutural, um campo de investigação que parece exigir mais aprofundamento para compreender como o racismo se desdobra através da linguagem e como a linguagem é desdobrada (senão criada ou recriada) através do racismo (NASCIMENTO, 2019).

\section{CONSIDERAÇÕES SOBRE OUTRAS MIRADAS POSSÍVEIS}

Estética e política parecem imbricadas de tal forma que talvez já não se possa falar em uma descolonização da estética sem mencionar os efeitos da colonização na política ou sem considerar como os espaços de decisão e participação ao comum são ocupados por uma maioria branca em um país de maioria populacional negra (preta e parda) e indígena. 
Desde a colonização, vivemos uma disputa de imagens por imaginários, que ganhou projeção mundial a partir da invenção da raça enquanto ideia instrumentalizada para capturar as imagens dos povos originários das Américas e de África, de modo que a exclusão dos racializados do regime de visibilidade não é só uma violência sistêmica: é uma violência atemporal.

Com o videodocumentário Roda o Tererê, porém, Lilian Solá Santiago realiza dois movimentos distintos, mas complementares: primeiro, ela se torna visível e, em segundo lugar, torna visível o povo Guarani Kayowá. A subversão nesse movimento não se limita ao que ela mostra e sim a como ela mostra, pois Lilian não é uma imagem; Lilian não está na tela. Lilian está por trás da tela como produtora de imagens, imaginações e imaginários.

Ao inscrever-se enquanto cineasta, deixa de ser representação cinematográfica. Sua câmera não mostra seus olhos; mostra o seu olhar. Lilian não transforma a sua câmera apenas em voz; transforma o microfone em ouvido, e faz dele uma caixa de ressonância para que as pessoas ouçam e vejam aqueles que vem sendo apagados, às vezes à bala, dos espaços do aparecer.

Ao transformar o colonialmente invisibilizado em protagonista da cena principal, não como memória (do passado), mas como movimento (no presente), o videodocumentário Roda o Tererê ajuda a tensionar o regime de visibilidade dominante, habituado a enquadrar indígenas e negros como figurantes em narrativas marginais.

Quando usa a câmera para representar os modos de viver, saber e fazer de grupos historicamente invisibilizados, Lilian Santiago contribui não só para a descolonização do olhar, como também para a descolonização da memória e do imaginário, mostrando que as raízes de muitas práticas sociais, que estruturam a sociedade nacional estão fincadas em territórios indígenas, negros, originários e tradicionais constantemente ameaçados de invasão, espoliação e depredação por essa mesma sociedade.

\section{REFERÊNCIAS}

BORGES, Rosane. Das perspectivas que inauguram novas visadas. In: bell Hooks. Olhares negros: raça e representação. São Paulo: Editora Elefante, 2019. Prefácio. pp.7- 29

CUSICANQUI, Silvia Rivera. La sociología de la imagen como praxis descolonizadora. In: CUSICANQUI, Silvia Rivera. Sociología de la imagen: ensayos. Ciudad Autónoma de Buenos Aires: Tinta Limón, 2015. pp. 13-31

FIGUEIREDO, Ângela. Descolonização do conhecimento no século XXI. In: SANTIAGO et al. Descolonização do conhecimento no contexto afro-brasileiro. 2ed. Cruz das Almas/BA: UFRB, 2019. 
GONZALEZ, Lélia. Por um feminismo afro-latino-americano. Caderno de formação política do círculo Palmarino, [S. 1.]: Batalha de ideias, n. 1., p. 12-21, 2011.

JACQUES, Rancière. A partilha do sensivel: estética e política. Ed. 34. Tradução de Mônica Costa Netto. São Paulo: EXO Experimental org., 2005

LUHMANN, Niklas. A realidade dos meios de comunicação. São Paulo: Paulus, 2005.

MEHREZ, Samia. The Bounds of race. Ithaca: Cornel University Press, 1991.

MOURA, Carolina. PM confunde guarda-chuva com fuzil e mata garçom no Rio, afirmam testemunhas. Disponível em: https://brasil.elpais.com/brasil/2018/09/19/politica/1537367458_048104.html. Acesso em 10 de ago 2020

NASCIMENTO, Abdias. O genocídio do negro brasileiro: processo de um racismo mascarado. 1ed. São Paulo: Perspectiva, 2016.

NASCIMENTO, Gabriel. Racismo linguístico: os subterrâneos da linguagem e do racismo. Belo Horizonte: Letramento, 2019.

ORLANDI, Eni Puchinelli. Terra à vista: discurso do confronto: Velho e novo mundo. São Paulo: Editora Cortez; Campinas: SPI Editora da Universidade Estadual de Campinas, 1990

PENAFRIA, Manuela. Análise de filmes: conceitos e metodologia(s). Lisboa, Portugal. VI Congresso SPCOM, abr. 2009

POTIGUARA, Eliane. Metade cara, metade máscara. $3^{a}$ edição. Rio de Janeiro: GRUMIN, 2019.

RAMOS, Natália. Contribuição do método fílmico para o estudo das representações sociais: perspectivas teóricas e de pesquisa. In: Moreira, Antonia Silva Paredes et al. Perspectivas teórico-metodológicas em representações sociais. João Pessoa> EDUFPB, 2005, p.365-400.

RAMOS, Natália. Perspectivas metodológicas em investigação: o contributo do método fílmico. Revista Portuguesa de Pedagogia, ano 37, n.3, 2003, p-35-62.

SANTIAGO, Lilian Solá. Vídeo "Roda o tereré” chega às cidades de Mato Grosso do Sul Disponível em: < http:// liliansantiago.blogspot.com/2009/12/video-roda-o-terere-chega-as-cidades-de.html> Acesso em 24 de ago. 2020

SCHUTZ, Alfred. Meios sociais de orientação e interpretação. In: WAGNER, Helmut. R. Fenomenologia e relações sociais: Textos escolhidos de Alfred Schutz. Rio de Janeiro: Zahar Editores, 1979. pp. 96-110.

SILVA, Juliano Gonçalves da. O indio no cinema brasileiro e o espelho recente. Paraná: Monstro dos Mares, 2020.

SILVA, Rosângela Souza da. A imagem que incomoda: identidade negra, educação e espaços sociais. In: SANTIAGO et al. Descolonização do conhecimento no contexto afro-brasileiro. 2ed. Cruz das Almas/BA: UFRB, 2019. 
SIMAS, Luiz Antonio; RUFINO, Luiz. Flecha no tempo. Rio de Janeiro: Mórula, 2019

QUIJANO, Anibal. Colonialidade do poder, eurocentrismo e América Latina. In: LANDER, Edgardo. $A$ colonialidade do saber: eurocentrismo e ciências sociais. Perspectivas latinoamericanas. Buenos Aires: CLACSO, 2005. pp.107- 126.

WILLIAM, Rodney. Apropriação cultural. São Paulo: Pólen, 2019. 